\title{
LA GEOLOGÍA, GEOMORFOLOGÍA, PEDOLOGÍA Y USO DE LA TIERRA EN LAS MUNICIPALIDADES DE PUERTO LÓPEZ (COLOMBIA) Y UBERLÂNDIA (BRASIL)
}

\author{
Geology, geomorphology, pedology and land use in \\ Puerto López (Colombia) and Uberlandia (Brazil) municipalities
}

Maryory Rodríguez Atehortúa Professora MSc. Depto Ingeniería Universidad Nacional de Colombia

Palmira/V - Colombia mrodrigueza@palmira.unal.edu.co

Yolanda Rubiano Sanabria Professora Dra. Facultad Agronomía Universidad Nacional de Colombia Santafé de Bogotá/C - Colombia yrubianos@unal.edu.co

Jorge Luis Silva Brito Professor Dr. do Instituto de Geografia da Universidade Federal de Uberlândia Uberlândia/MG - Brasil jbrito@ufu.br

Silvio Carlos Rodrigues Professor Dr. do Instituto de Geografia da Universidade Federal de Uberlândia Uberlândia/MG - Brasil silgel@ufu.br

Artigo recebido para publicação em 21/01/2010 e aceito para publicação em 05/04/2010

RESUMEN: Debido a la preocupación en elevar la calidad de vida de los habitantes en Brasil y en Colombia, se desarrollaron estudios aislados para conocer los principales recursos físicos y humanos y así, establecer normas para una adecuada administración y aprovechamiento del territorio. El objetivo de este trabajo fue mapear y comparar la geología, la geomorfología, los suelos y el uso de la tierra y cobertura vegetal natural, de las altillanuras en los municipios de Uberlândia (Brasil) y Puerto López (Colombia). Fue utilizado el Sistema de Procesamiento de Informaciones Georreferenciadas (SPRING) para el almacenamiento, manipulación y procesamiento de informaciones colectadas en el campo y en las imágenes de satélite. Los resultados muestran que existen variadas e importantes diferencias entre los municipios de Puerto López y Uberlândia, lo que hace que sea reconsiderada la idea de hacer transferencias de paquetes tecnológicos no modificables, en relación a las condiciones propias de cada lugar, donde serán implementados. No es recomendable usar deliberadamente los mismos métodos o tecnologías para la producción agrícola en los dos municipios.

Palabras-clave: Sabana. Suelos. Uso de las tierras. SIG. 
La geología, geomorfología, pedología y uso de la tierra en las municipalidades de Puerto López (Colombia) y Uberlândia (Brasil) Maryory Rodríguez Atehortúa, Yolanda Rubiano Sanabria, Jorge Luis Silva Brito, Sílvio Carlos Rodrigues

ABSTRACT: On account of the precaution to raise the quality of life for people in Brazil and Colombia, isolated studies were developed to know the main human and physical resources and thus establish standards for proper management and exploitation of the territory. The aim of this study was to map and compare the geology, geomorphology, soils and land use and natural vegetation of the high plains in the municipalities of Uberlândia (Brazil) and Puerto López (Colombia). Georeferenced Information System Processing was used (SPRING) for storage, handling and processing of information collected in the field and satellite imagery. The results show that there are many important differences between the municipalities of Puerto Lopez and Uberlândia, which makes reconsidered the idea of transfer of technology packages do not coded in relation to the conditions of each place where they will be implemented. Deliberately do not recommend using the same methods or technologies for agricultural production in the two municipalities.

Keywords: Savanna. Soil. Land use. GIS.

\section{INTRODUCCIÓN}

Al interior de cada país, se encuentran territorios que se supone, tienen características similares o factores comunes de formación, como son, los Llanos Orientales (Sabanas) de Colombia y los "Cerrados" (Sabanas) de Brasil. Las características mencionadas son las siguientes: Los suelos de la Orinoquía colombiana fueron originados de materiales transportados como, sedimentos aluviales (Pleistoceno antiguo) dispuestos en series alternantes, sedimentos fluviales y eólicos (IGAC, 1997). Se considera también que esos suelos tienen su origen de materiales que proceden del antiguo Escudo Guayanés, que tienen su prolongación desde el Brasil (FRANCO, 1998). Los "Cerrados" (= Sabanas) brasileros son considerados "un manantial de recursos" donde pueden desarrollarse actividades agropecuarias extractivas y silviculturas favorecidos por el clima. Sus suelos son de baja fertilidad, pero cuentan con buenas condiciones físicas y topográficas que permiten la mecanización y la implementación de prácticas culturales con técnicas adecuadas, para producir abundantes cosechas (INFORME AGROPECUARIO, 1980).

Se considera que los suelos de la Orinoquía colombiana son químicamente infértiles, con un desarrollo físico considerable (FRANCO, 1998). Sin embargo, las propiedades físicas pueden cambiar, de manera que se ocasione la degradación de los suelos, dependiendo del manejo (AMEZQUITA, 1998). Esta área tiene alto potencial agrícola y pecuario, aún así, es necesario hacer prácticas culturales ajustadas a las condiciones de la misma. Los "Llanos Orientales" son considerados potencialmente como "La despensa agrícola de Colombia". Se dice que, ambos países hacen parte de la llamada "Frontera agrícola más importante del mundo".

La baja fertilidad de los suelos impide, en gran parte, el desarrollo de las regiones al imposibilitar la intensificación agropecuaria. Aún así, se puede decir que el uso de la tierra no es adecuado para tener una productividad agrícola sustentable en el tiempo y los beneficios ecológicos de las áreas naturales.

Este estudio se fundamentó en la hipótesis de que hay diferencias entre las características físicas y químicas de los suelos de la altillanura brasilera (Cerrado) y de la "Altillanura" colombiana (sabanas), medidas en la superficie y a través del perfil del suelo. Esta hipótesis resultó verdadera, lo que dio lugar a una segunda hipótesis que considera los diferentes tipos de manejo de suelos con relación a la transferencia de tecnología agropecuaria, así como también a la generalización de información de suelos.

El objetivo principal de este trabajo fue comparar las características físicas de la geología, la geomorfología y de la pedología, de las áreas planas de 
los municipios de Uberlândia (Brasil) y Puerto López (Colombia), mediante la elaboración de mapas temáticos y de la evaluación de datos pedológicos existentes.

\section{LOCALIZACIÓN DEL ÁREA DE ESTUDIO}

El municipio de Uberlândia (Brasil) está localizado entre las coordenadas geográficas $18^{\circ} 34^{\prime}$ y $19^{\circ}$ $14^{\prime}$ de latitud sur, y $47^{\circ} 03^{\prime}$ y $48^{\circ} 50^{\prime}$ al oeste Greenwich, ocupa una superficie de cerca de $4.192 \mathrm{Km}^{2}$ su altitud media, con relación al nivel del mar, es de 863 m; 1500 mm (ROSA et al , 1991).

Puerto López (Colombia) está localizado entre las coordenadas geográficas $72^{\circ} 24^{\prime}$ y $73^{\circ} 25^{\prime}$ de longitud al oeste de Greenwich y, $3^{\circ} 06^{\prime}$ y $4^{\circ} 44^{\prime}$ de latitud norte. Su área es de $6248 \mathrm{Km}^{2}$; su altitud media es de 182 metros con relación al nivel del mar, y (LEON, 1999).

\section{MATERIALES Y MÉTODOS}

Fue considerada la metodología de Análisis Fisiográfico creada por el Centro de Investigación en Percepción Remota - CIAF, del Instituto Geográfico Agustín Codazzi (IGAC). Fueron seleccionados para la comparación factores geográficos, climáticos, de geo-génesis, material parental de los suelos (edad), suelos, vegetación natural y uso de las tierras.

Se utilizaron los estudios existentes, para hacer la comparación de los factores mencionados, en relación con las cualidades del suelo y los tipos de manejo practicados a través del tiempo.

Se implemento también la metodología propuesta por Libault (1971), "los cuatro niveles de la investigación geográfica", para el desarrollo de este trabajo, que comprende: recolección y selección de la información necesaria para la investigación, correlación de los datos para posteriormente ser interpretados, interpretación de los datos seleccionados hasta conseguir los resultados $\mathrm{y}$, representación de los resultados en forma de cartogramas o gráficos". En nuestro caso fueron elaborados diversos mapas a escala 1:100.000, usando el módulo SCARTA 4.0 del software SPRING 4.0.

Fueron utilizados informes de proyectos, ma- pas (suelos, geología, geomorfología, cobertura vegetal, entre otros), fotografías aéreas, imágenes de satélite TM Landsat.

\section{Procedimientos técnicos operacionales}

Se elaboraron los mapas temáticos (de hipsometría, pendientes, geomorfología, y de uso de la tierra y cobertura natural) de los municipios, a partir de las bases cartográficas a escala 1:100.000.

Para los mapas hipsométricos, se utilizaron curvas de nivel.

Para la elaboración de los mapas de uso y cobertura vegetal natural de la tierra, se utilizó la información contenida en imágenes de satélite Landsat TM, complementada por verificaciones sistemáticas en campo.

Se realizaron las siguientes operaciones: Lectura de imágenes, la lectura y exportación de las imágenes se hizo con el módulo IMPIMA del software SPRING; registro, con 11 puntos de control para cada área de estudio en el módulo SPRING. El error cuadrático medio fue de 35,00 metros; contraste de las imágenes, etapa en el pre-procesamiento para diferenciar los patrones representados; composición a color, azul (TM3), rojo (TM4) y verde (TM7) para Uberlandia y, azul (TM3), rojo (TM4) y verde (TM5) para Puerto López.

Seguidamente, fueron generadas las cartas imagen, utilizando el módulo SCARTA, sobreponiendo las composiciones a color a la red hidrográfica, las vías y el límite de los municipios.

\section{RESULTADOS Y DISCUSIÓN}

\section{Factores biofísicos}

\section{- El Clima}

El régimen de humedad de los suelos predominante en el municipio de Puerto López es Údico), mientras que en el municipio de Uberlândia es Ústico.

La precipitación media anual en Puerto López es de $2588 \mathrm{~mm}$, mayor que en Uberlandia, cuyo valor es de $1500 \mathrm{~mm}$, y representa un limitante para a implementación de cultivos. El comportamiento de la 
precipitación en ambos casos es monomodal. Siendo los meses lluviosos de abril a julio y los secos de diciembre a marzo en Puerto López y, en Uberlândia, los lluviosos de octubre a abril y los secos de mayo a agosto.

Las temperaturas promedio también son diferentes: en Puerto López es de $27^{\circ} \mathrm{C}$, lo que indica una condición isohipertérmica; en Uberlândia, el promedio de temperatura es de $22^{\circ} \mathrm{C}$, correspondiendo a condiciones hipertérmicas.

En el trópico, la distribución de las lluvias determina el mejor período de siembra. Generalmente, los cultivos requieren buena cantidad de agua en los primeros días después de haber sido sembrados, por esta razón, se hace coincidir con el inicio o durante la época de las lluvias. El consumo de agua de los cultivos es determinado, básicamente, por la demanda de evaporación de la atmósfera, propiedades del suelo y características de las plantas" (BERGAMASCHI, 1992 citado por MICHELON et al., 2004). De esta forma, el agua es el factor que más puede afectar el rendimiento de los cultivos.

En el municipio de Uberlandia, la época preferencial para la siembra es el mes de octubre y en el municipio de Puerto López, el mes de abril. Estos meses corresponden al inicio de las lluvias en cada área.

\section{- La Geología}

Las edades geológicas indican que los materiales de formación de Puerto López son más recientes que los de Uberlândia (períodos Arqueano y Mesozoico respectivamente).

En relación con la litología en Puerto López, dominan areniscas (cuarzo, feldespato, moscovita), shales, lutitas y cherts que se asocian a una fertilidad potencial de los suelos baja, y coincidente con el ambiente intemperico en el que evolucionaron los minerales constituyentes del suelo (CUADRO 1).

\begin{tabular}{|l|l|c|c|}
\hline \multicolumn{1}{|c|}{ Litologías } & $\begin{array}{c}\text { Susceptibilidad } \\
\text { al intemperismo }\end{array}$ & $\begin{array}{c}\text { Fertilidad } \\
\text { potencial }\end{array}$ \\
\hline \multirow{4}{*}{ Areniscas } & $\begin{array}{l}\text { Cuarzo } \\
\text { Feldespato } \\
\text { Moscovita }\end{array}$ & $\begin{array}{c}\text { Difícil } \\
\text { Media / Alta } \\
\text { Media / Baja }\end{array}$ & BAJA \\
\hline Esquistos & $\begin{array}{l}\text { Mo\% sílice } \\
35 \% \text { arcilla caolinita } \\
\text { Micas } \\
15 \% \text { material Autigénicos }\end{array}$ & $\begin{array}{l}\text { Dedia / Alta } \\
\text { Media / Alta } \\
\text { Media / Baja }\end{array}$ & MEDIA \\
\hline \multirow{2}{*}{ Lutitas } & $\begin{array}{l}\text { Rocas de arcilla (mayor porcentaje) } \\
\text { y/o sílice }\end{array}$ & Difícil & MEDIA \\
\hline Cuarzo - Areniscas & Difícil & BAJA \\
\hline
\end{tabular}

CUADRO 1: Características litológicas del municipio de Puerto López. Organizó.: Rodríguez (2004).

En tanto que las litologías encontradas en Uberlândia, migmatitas (plagioclasa, biotita, cuarzo), gneis (cuarzo, feldespato, micas, anfibolitos), granito, areniscas (cuarzo, feldespato, moscovita), esquistos (micas, cuarzo, feldespato) y basalto (plagioclasa cálcica, nefelina, piroxenos, cuarzo, olivino) están cons- tituidas por minerales que condicionan la fertilidad potencial del suelo de media a alta (CUADRO 2).

Este factor hace que la composición mineralógica de las fracciones arena y arcilla sea diferente, lo que evidencia la fertilidad potencial y actual más baja en Puerto López que en Uberlândia, ya que los 
elementos resultantes del material parental contienen minerales de fácil intemperismo $\mathrm{y}$, probablemente, aportarán mayor cantidad de bases.

Características, tales como la baja capacidad de intercambio catiónico y alta capacidad de adsorber fósforo de los óxidos de hierro y de aluminio, y de igual forma, de la caolinita, son contrarias a las de, por ejemplo, los minerales de arcilla 2:1 que tienen alta capacidad de intercambio de cationes y pueden fijar potasio y amonio. Esto hace que la interpretación mineralógica sea bien importante en la previsión del comportamiento de este suelo.

\section{- La Geomorfología}

Entre las áreas planas de los municipios, se observan similitudes en cuanto a las características del relieve, ya que en estos, se encuentran Unidades Morfo estructurales de Altillanura Tabular y Patrones de Forma semejantes o Unidades Morfológicas que son, en la mayor parte, de Denudación con modelado tabular (Dt), Denudación modelado convexo (Dc) y Acumulación del tipo fluvial (Apf). Los índices de disección del relieve son también muy semejantes (ver FIGURAS 1, 2, 3 y 4 ).

En relación con el suelo, las unidades de suelos corresponden a determinadas unidades geomorfológicas, tanto en Puerto López, como en Uberlândia (ver FIGURA 5 y 6). El significado de los símbolos en los mapas son:

- Uberlandia. Latossolo Vermelho-Amarelo ácrico típico (LVAw), Latossolo Vermelho (LVa), Latossolo Vermelho distroférrico (LVdf), Argissolo Vermelho-Amarelho eutrófico (PVAe), Cambissolo Háplico Alumínico típico (CXa1) y Gleissolo Hápico Tb (Gxbe). - Puerto López. Typic Hapludox [Latossolo] (a1), Typic Haplustox-Oxic Dystrudepts [Cambissolo] (b1) y Oxiaquic Dystrudepts-Typic Fluvaquents [Neossolo] (h1).

\begin{tabular}{|c|c|c|c|}
\hline \multicolumn{2}{|r|}{ Litologías } & \multirow{2}{*}{$\begin{array}{c}\text { Susceptibilidad al intemperismo } \\
\text { Media / Alta } \\
\text { Difícil } \\
\text { Media }\end{array}$} & \multirow{2}{*}{$\begin{array}{c}\text { Fertilidad potencial } \\
\text { BAJA / ALTA }\end{array}$} \\
\hline Migmatitos & $\begin{array}{l}\text { Plagioclasa } \\
\text { Cuarzo } \\
\text { Biotita } \\
\text { Microclina }\end{array}$ & & \\
\hline Genais & $\begin{array}{l}\text { Cuarzo } \\
\text { Feldespato } \\
\text { Micas } \\
\text { Anfibolitos }\end{array}$ & $\begin{array}{c}\text { Difícil } \\
\text { Media / Alta } \\
\text { Media } \\
\text { Media / Alta }\end{array}$ & MEDIA / ALTA \\
\hline Granito & Cuarzo (mayor proporción) & Difícil & BAJA \\
\hline Areniscas & $\begin{array}{l}\text { Cuarzo } \\
\text { Feldespato } \\
\text { Moscovita }\end{array}$ & $\begin{array}{c}\text { Difícil } \\
\text { Media / Alta } \\
\text { Media / Baja }\end{array}$ & BAJA \\
\hline Esquistos & $\begin{array}{l}\text { Micas } \\
\text { Cuarzo } \\
\text { Feldespato }\end{array}$ & $\begin{array}{c}\text { Media } \\
\text { Difícil } \\
\text { Media / Alta }\end{array}$ & BAJA / ALTA \\
\hline Basalto & $\begin{array}{l}\text { Plagioclasa cálcica } \\
\text { Piroxenos } \\
\text { Olivino } \\
\text { Cuarzo } \\
\text { Nefelina }\end{array}$ & $\begin{array}{c}\text { Media / Alta } \\
\text { Alta } \\
\text { Alta } \\
\text { Difícil }\end{array}$ & MEDIA / ALTA \\
\hline
\end{tabular}

CUADRO 2: Características litológicas del municipio de Uberlandia. Organizó.: Rodríguez (2004). 


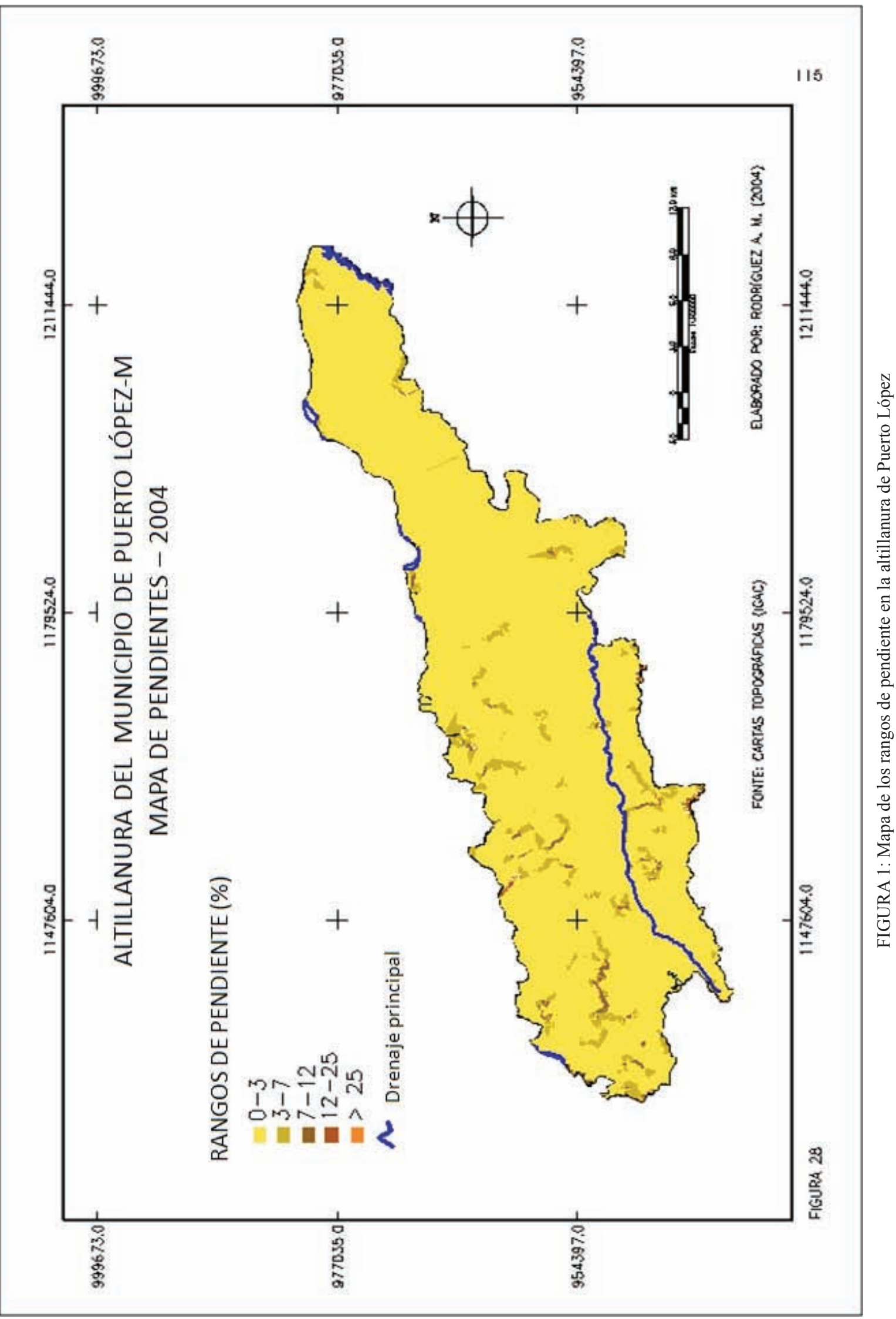

Sociedade \& N atureza, U berlândia, 22 (2): 329-345, ago. 2010 


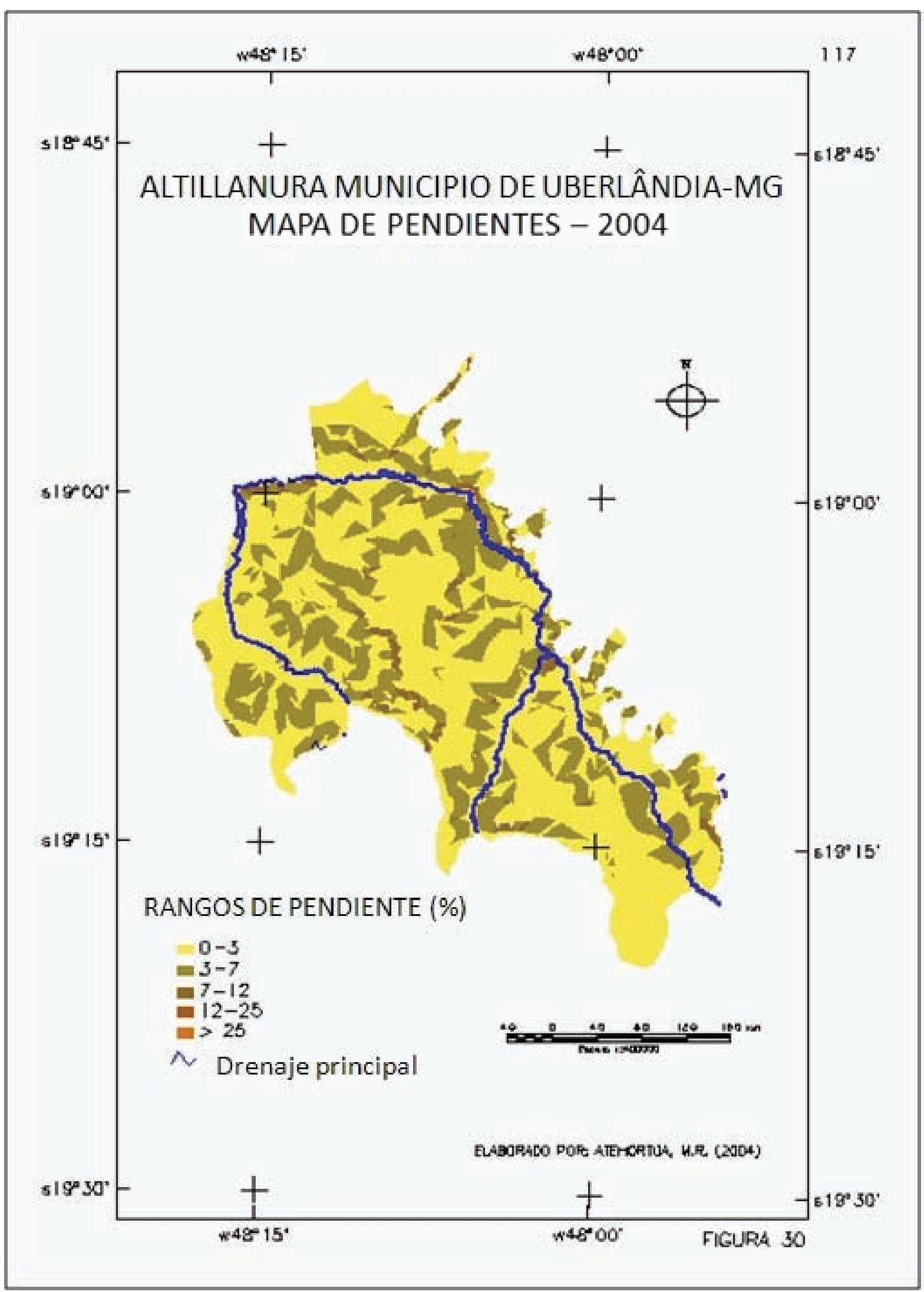

FIGURA 2: Mapa de los rangos de pendiente en la altillanura de Uberlândia. 


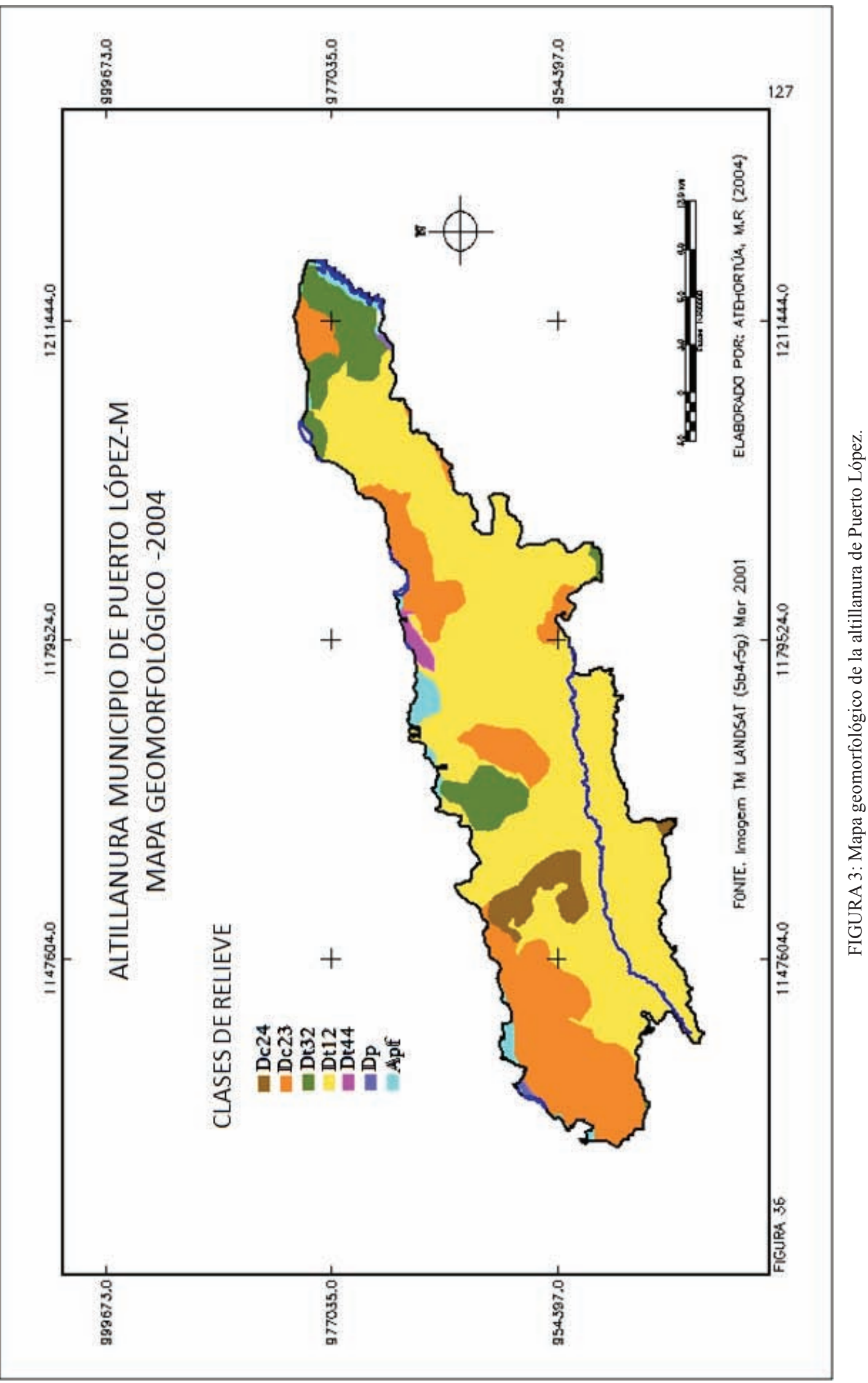

Sociedade \& N atureza, U berlândia, 22 (2): 329-345, ago. 2010 


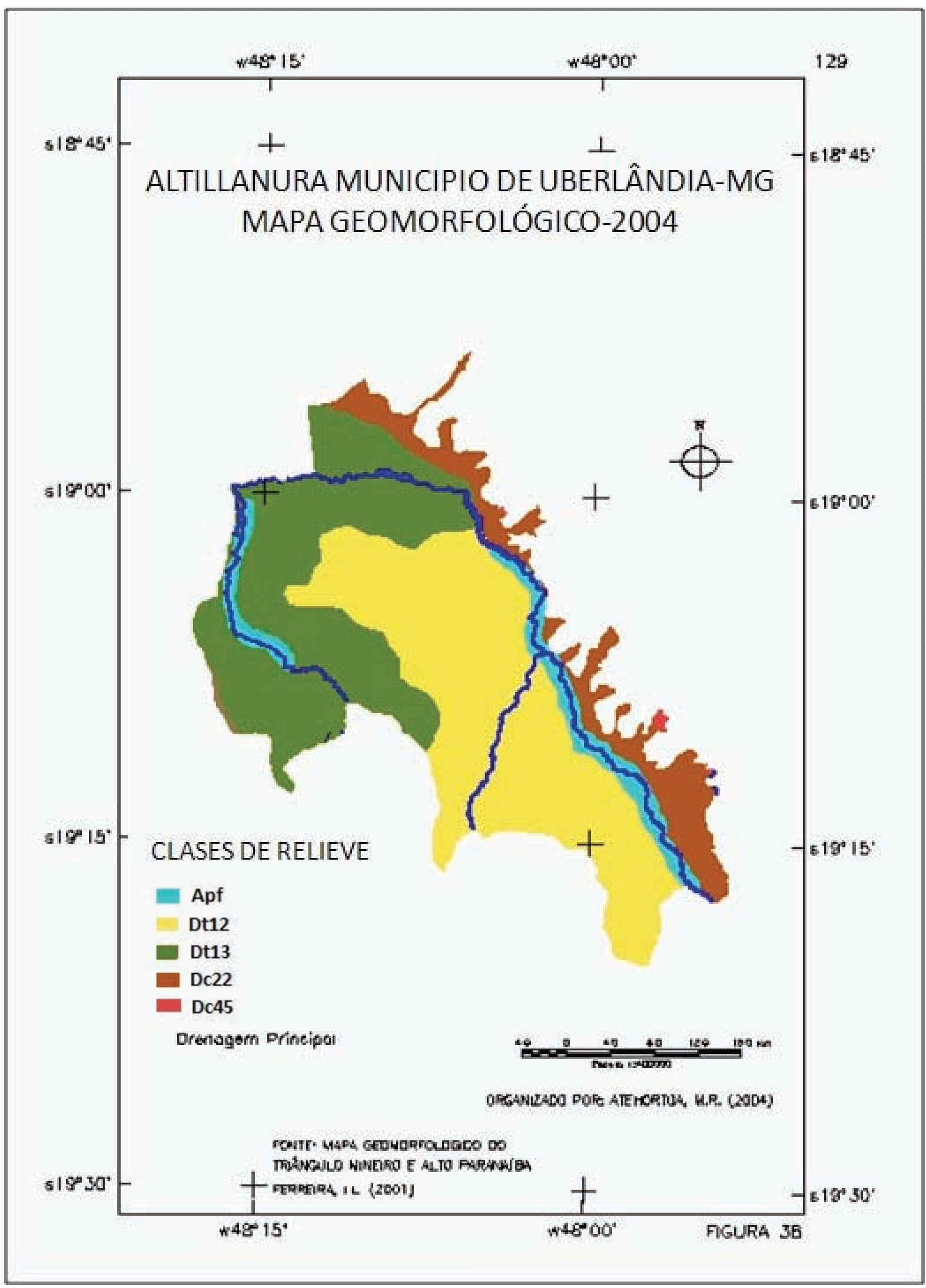

FIGURA 4: Mapa geomorfológico de la altillanura de Uberlândia. 


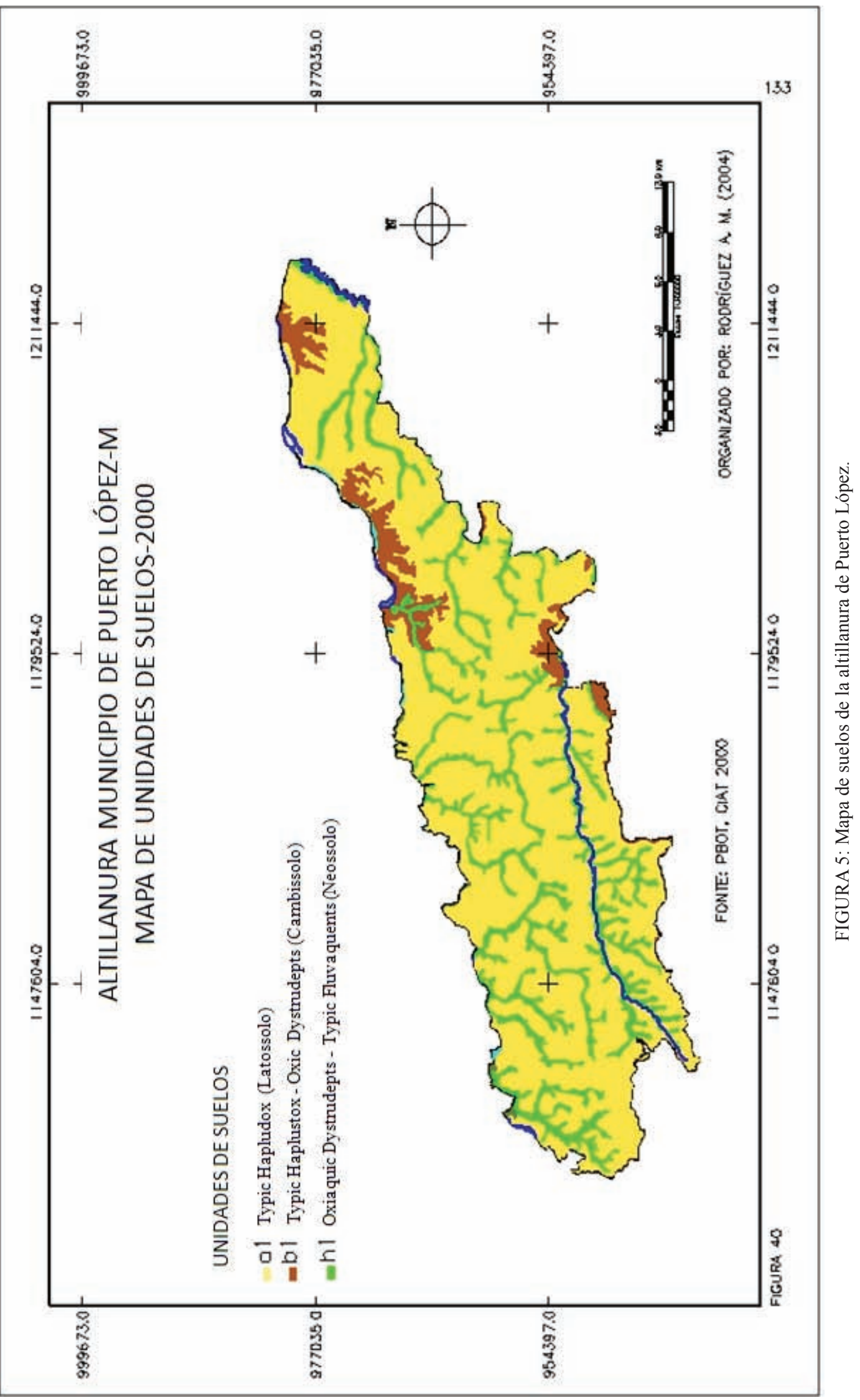

Sociedade \& N atureza, U berlândia, 22 (2): 329-345, ago. 2010 


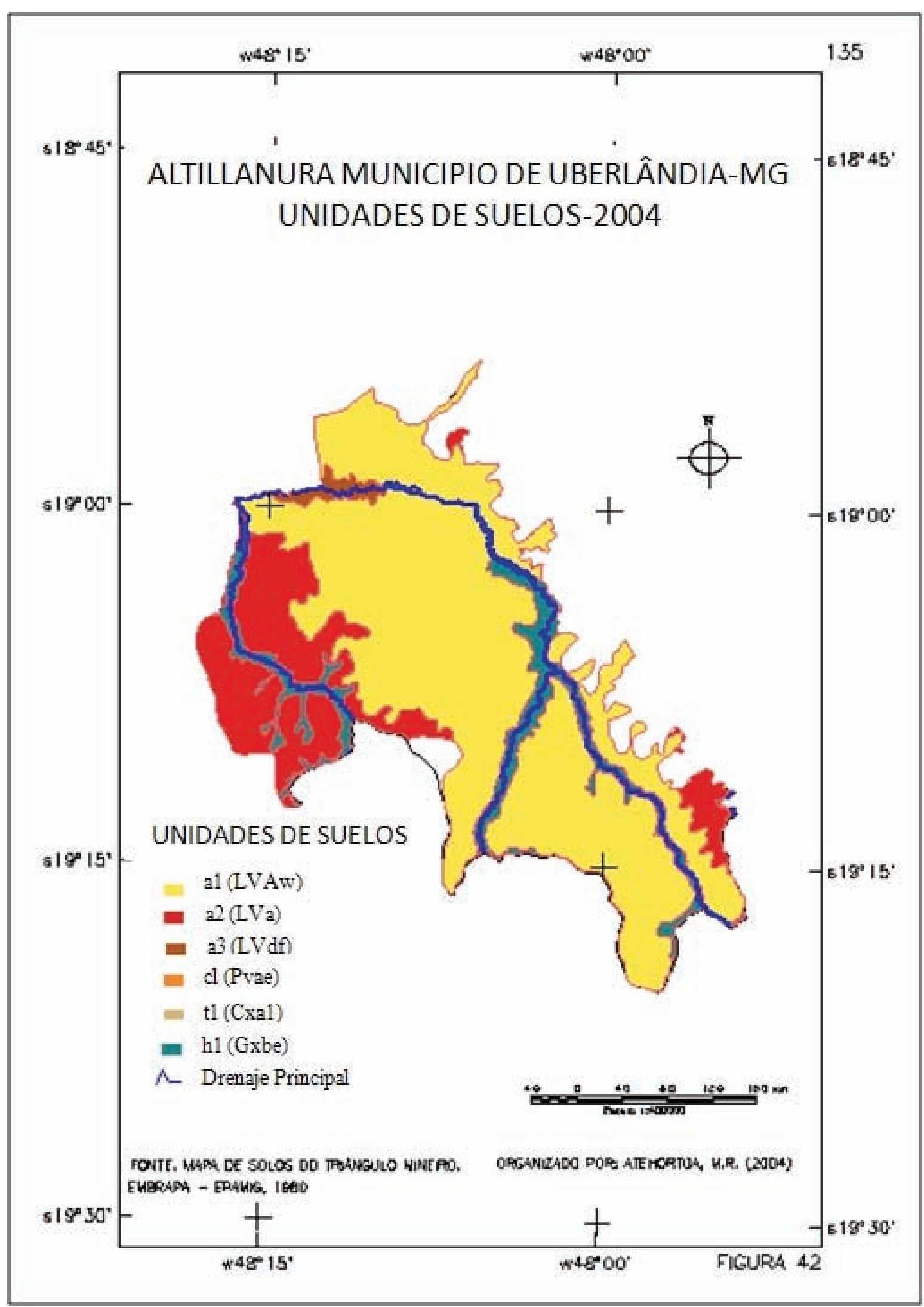

FIGURA 6: Mapa de suelos de la altillanura de Uberlândia. 
- Pedología

En los dos municipios predominan, los Oxisoles (Latosoles/Brasil) al nivel de Orden, y diferentes tipos de Oxisoles al nivel de Suborden, correspondiendo a las diferencias en las características químicas, físicas e influencia del relieve. Sin embargo, aunque los tipos de suelos indiquen semejanza, no es posible afirmar que los suelos de los municipios son iguales entre sí, ya que los factores geológico y litológico (CUADROS 1 y 2) determinan las características que más diferencian la potencialidad productiva (fertilidad) de estos suelos.

La susceptibilidad al intemperismo de los materiales litológicos que constituyen los suelos del municipio de Puerto López es baja, lo que hace que la fertilidad potencial de esos suelos también sea baja, caracterizándolos como pobres. Este hecho genera la necesidad de hacer una planificación de tipos de manejo moderados, considerando mayor utilización de abono químico y prácticas mayores de conservación.

En Uberlândia, la situación cambia, ya que los materiales litológicos de sus suelos son más antiguos y presentan una susceptibilidad al intemperismo mayor que en los de Puerto López. Sin embargo, esto no quiere decir que estos suelos no necesitan de manejo adecuado y de buenas prácticas de conservación, pero si, que es posible implementar en ellos una mayor variedad de cultivos, cuyos requerimientos agronómicos (de fertilidad) son altos.

Probablemente, el aspecto más determinante está relacionado con las propiedades dinámicas del suelo, que no cambia la taxonomía, pero que si afecta el uso y el manejo del mismo.

\section{Propiedades químicas}

Como es conocido, los suelos de los cerrados/ sabana son de fertilidad baja. La acidez del suelo es uno de los factores más limitantes de la productividad de los cultivos, debido a problemas de deficiencia y/o toxicidad nutricional, baja capacidad de retención de agua y baja actividad de los microorganismos.

Para compensar la falta de productividad de esos suelos, es necesaria la aplicación de correctivos agrícolas como la aplicación de cal (encalado) para corregir los excesos de Aluminio.

A partir de los datos obtenidos (CUADRO 4), puede observarse que las propiedades químicas difieren notablemente en cuanto a la suma de las bases (S), siendo que en el suelo de Uberlândia, la $\mathrm{S}(1,42 \mathrm{cmol} / \mathrm{Kg})$ es mayor que en el Suelo de Puerto López $(0,24 \mathrm{cmol} / \mathrm{Kg})$.

Los valores del Al, 2,1 ppm en Uberlândia y de 2,31 ppm en Puerto López, sobrepasan el nivel crítico aceptable de $1 \mathrm{ppm}$, reportada por Amézquita \& Quintero (2004).

Según Kiehl (1979), en suelos con pH menores que 5,0, habrá deficiencia de elementos $\mathrm{Ca}, \mathrm{Mg}$, $\mathrm{P}, \mathrm{Mo}, \mathrm{B}$ o toxicidad por Al, Mn, Zn y otros metales pesados, debido a que su solubilidad es más alta. En este caso, se puede decir que los suelos de los lugares estudiados presentan toxicidad por Al, requiriéndose el uso de correctivos para mejorar la fertilidad de los suelos.

\section{Propiedades físicas}

La densidad aparente es una de las propiedades físicas que determinan el estado de un suelo, antes y después de la labranza y es a partir de esa característica que se pueden analizar otras, como la porosidad total, el tamaño y la continuidad de poros. "La porosidad y la macro porosidad decrecen linealmente con el aumento de la densidad del suelo" (STONE et. al., 2002) y el crecimiento de las raíces es perjudicado.

En Brasil, se encuentran densidades aparentes menores e iguales a 1 , que comparadas con densidades aparentes de Puerto López (mayores a 1,4), son menores y más convenientes para el desarrollo de los cultivos.

Otro factor fuertemente relacionado con la densidad y la porosidad del suelo es la resistencia a la penetración (CUADRO 3), la cual aumenta ala vez que aumenta la densidad del suelo (STONE et. al., 2004).

En algunas prácticas hechas en Brasil, se encontraron valores de resistencia a la penetración de 2.5 $\mathrm{MPa}$, hecho que propició el bajo desarrollo de raíces observado (AMÉZQUITA, 2004. Comunicación personal).

Otros estudios, desarrollados por Rosolem et al. (1999) mostraron que con una resistencia del suelo a la penetración igual a 1,3 $\mathrm{MPa}$, el crecimiento de las raíces seminales adventicias del maíz, fue reducido a la mitad. 
La geología, geomorfología, pedología y uso de la tierra en las municipalidades de Puerto López (Colombia) y Uberlândia (Brasil) Maryory Rodríguez Atehortúa, Yolanda Rubiano Sanabria, Jorge Luis Silva Brito, Sílvio Carlos Rodrigues

\begin{tabular}{|ccccc|}
\hline \multirow{2}{*}{$\mathrm{ds}^{*}\left(\mathrm{Kg} \mathrm{dm}^{-3}\right)$} & Potal & Macro & Micro & $\mathrm{R} * *(\mathrm{MPa})$ \\
\cline { 2 - 4 } & 0,625 & 0,288 & 0,337 & 0,1 \\
1,0 & 0,550 & 0,220 & 0,330 & 1,0 \\
1,2 & 0,476 & 0,131 & 0,345 & 1,7 \\
1,6 & 0,401 & 0,036 & 0,365 & 6,1 \\
\hline
\end{tabular}

$*$ ds densidad del suelo

** $\mathrm{R}$ - resistencia del suelo a la penetración

CUADRO 3: Porosidad y resistencia del suelo a la penetración en relación con la densidad del Suelo. Fuente: Stone et. al. (2004).

En Puerto López, se han implementado algunos ensayos de Siembra Directa por parte del Centro Internacional de Agricultura Tropical, para determinar la viabilidad de extensión de este tipo de manejo, con relación mejoramiento y conservación del suelo.

La labranza de poca profundidad, hecha con rastra de discos, ha generado problemas como sellamiento y encostramiento superficial, alta densidad aparente, compactación, baja velocidad de infiltración, alta susceptibilidad a la erosión en suelos recientemente preparados y alta producción de escorrentía (GARCES et. al., 2004).

En la actualidad, en el Centro Internacional de Agricultura Tropical generó la posibilidad de crear una capa arable productiva, que constituye el desarrollo de una capa superficial con poco o ningún limitante físico, químico o biológico.

Después de tres años implementando esta práctica, hubo incrementos con relación al cerrado/sabana natural, sin intervención, en 2 a 5 veces las tasas de infiltración de agua en el suelo, en 13 a $21 \%$ en la porosidad total, reducciones en la resistencia a la penetración por las raíces entre un 60 a $80 \%$, disminuciones en la resistencia tangencial horizontal a la expansión radicular entre 50 a $65 \%$ y una disminución de la compactación del suelo entre 10 y $15 \%$. De esta manera, los rendimientos de los cultivos adaptados al área aumentaron del segundo para el tercer año y, fue posible, sembrar al tercer año materiales de cultivos de alto rendimiento (MAR), los cuales presentaron mayores niveles de producción en comparación a los cultivos adaptados (GARCES et. al, 2004).

En un estudio realizado en Uberlândia, para evaluar los atributos de un suelo sometido a diferentes sistemas de manejo, Jorge (2003) hubo diferencias significativas entre los sistemas de manejo cultivo convencional con calcáreo + yeso agrícola y con calcáreo; ausencia de preparación del suelo con calcáreo + yeso agrícola y con calcáreo, aplicados en la superficie (sin incorporación); cultivo mínimo con calcáreo y con calcáreo + yeso agrícola, parcialmente incorporados con arado escarificador; y siembra directa con calcáreo + yeso agrícola incorporados con rastra en el primer año agrícola.

Se determinaron valores de $\mathrm{pH}$ en agua, calcio, magnesio y aluminio, mayores con el sistema convencional y siembra directa (con incorporación) con relación a la labranza mínima y ausencia de preparación.

En cuanto a las características físicas del suelo, no hubo efecto significativo del correctivo (calcáreo o calcáreo + yeso) sobre la densidad y la resistencia a la penetración. El sistema convencional, presentó menores valores de resistencia a la penetración, pero hubo un aumento progresivo de los valores de densidad del suelo y resistencia a la penetración en profundidad.

En Brasil, áreas que desde la década de los 60 solo tenían pastos, principalmente brachiaria, sin la debida corrección del suelo, hoy son usadas en la producción de granos, después de haber recuperado adecuadamente los suelos. Sin embargo, los rendimientos son bajos, como resultado de la inadecuación tecnológica, a la dominancia del monocultivo de soya, a la baja fertilidad natural o degradación del suelo, y también a las imperfecciones en el gerenciamiento del agro negocio (KLUTHCOUSKI et. al., 2004).

Según Kluthcouski et. al., (2004), a pesar del surgimiento de la Siembra Directa, persiste la erosión del suelo, debido a la ineficiente cobertura con paja y, la contaminación de las aguas con sedimentos y fertilizantes utilizados en la labranza. 
La geología, geomorfología, pedología y uso de la tierra en las municipalidades de Puerto López (Colombia) y Uberlândia (Brasil) Maryory Rodríguez Atehortúa, Yolanda Rubiano Sanabria, Jorge Luis Silva Brito, Sílvio Carlos Rodrigues

\begin{tabular}{|lcc|}
\hline \multicolumn{1}{|c|}{ Variable } & Puerto López & Uberlândia \\
\hline D.A. $(\mathrm{g} / \mathrm{cc})$ & 1,46 & 1,44 \\
\hline $\mathrm{M} . \mathrm{O} .(\%)$ & 2,98 & 2,20 \\
\hline $\mathrm{P}(\mathrm{ppm})$ & 1,27 & 1,31 \\
\hline $\mathrm{Ca}(\mathrm{cmol} / \mathrm{Kg})$ & 0,11 & 0,87 \\
\hline $\mathrm{Mg}(\mathrm{cmol} / \mathrm{Kg})$ & 0,07 & 0,55 \\
\hline $\mathrm{K}(\mathrm{cmol} / \mathrm{Kg})$ & 0,06 & 0,004 \\
\hline $\mathrm{Al}(\mathrm{ppm})$ & 2,31 & 2,10 \\
\hline $\mathrm{S}(\mathrm{cmol} / \mathrm{Kg})$ & 0,24 & 1,42 \\
\hline Infiltración $(\mathrm{cm} /$ hora $)$ & 8,00 & 13,00 \\
\hline Porosidad total $(\%)$ & 45 & 45 \\
\hline Resistencia a la penetración $\left(\mathrm{Kg} / \mathrm{cm}^{2}\right)$ & 10,00 & 19,00 \\
\hline $\begin{array}{l}\text { Teor de agregados del suelo estables } \\
\text { en agua }(\%), \text { tamaño }>2 \text { mm }\end{array}$ & 84 & 59 \\
\hline
\end{tabular}

CUADRO 4: Características químicas y físicas medias de los suelos de la altillanura de Puerto López y Uberlândia $(0$ a $20 \mathrm{~cm})$. Fuente: Amézquita y Quintero (2004).

A continuación se presentan algunos datos (CUADRO 4) de algunos parámetros físicos y químicos, de los suelos en cada municipio.

\section{El Uso de la Tierra y Cobertura Vegetal Natural}

Hay poca representación de cultivos y mayor cobertura de pastos introducidos en Puerto López, mientras que en Uberlândia predomina la práctica de cultivos anuales.

Estos hechos tienen relación con la fertilidad de los suelos en cada área y al desarrollo de nuevas tecnologías, en el caso de Brasil. Los cultivos implementados en Puerto López son: maíz, millo, yuca, arroz, fríjol, soya, frutales, palma africana. El sistema de labranza usado en este municipio es el convencional.

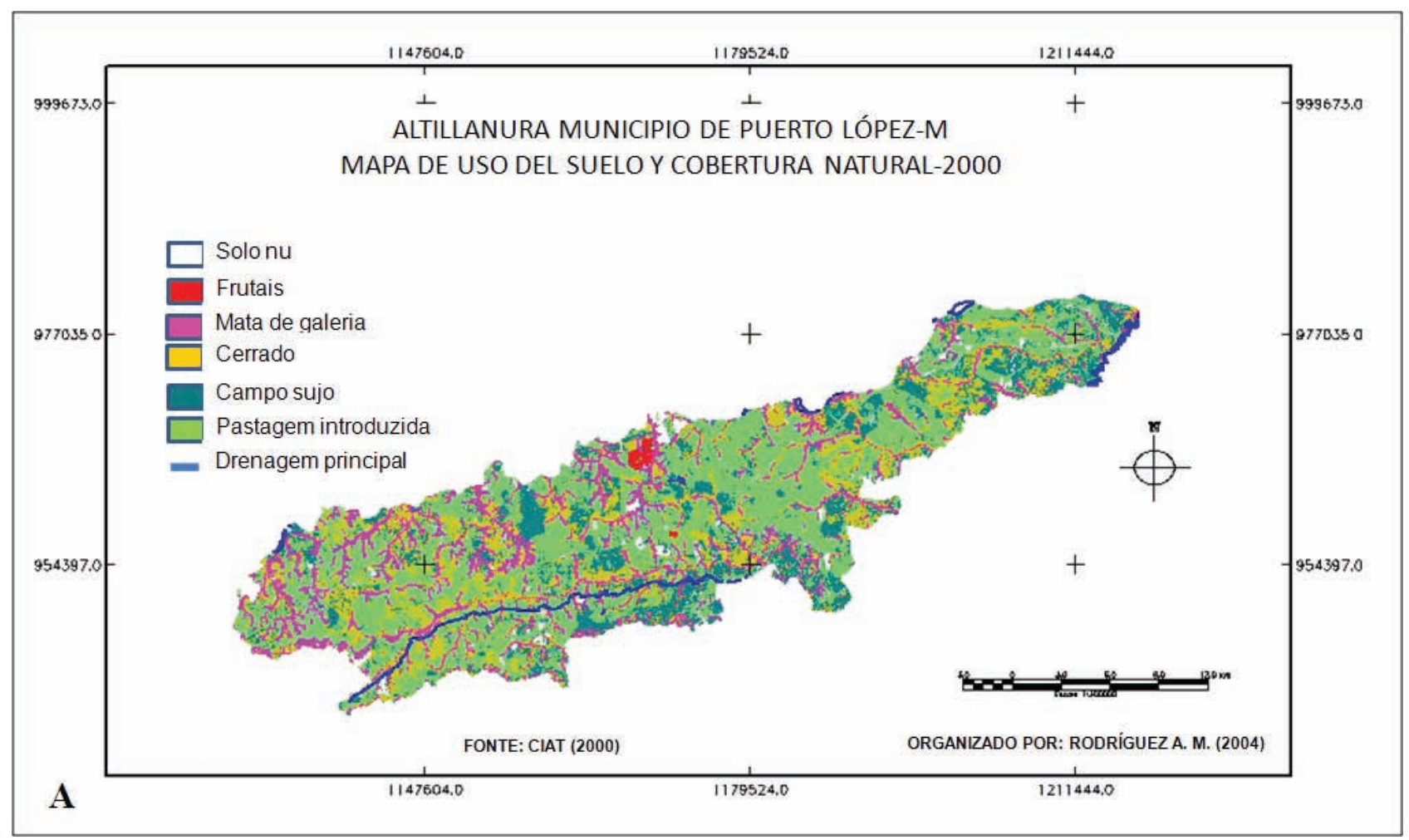

Sociedade \& N atureza, U berlândia, 22 (2): 329-345, ago. 2010 


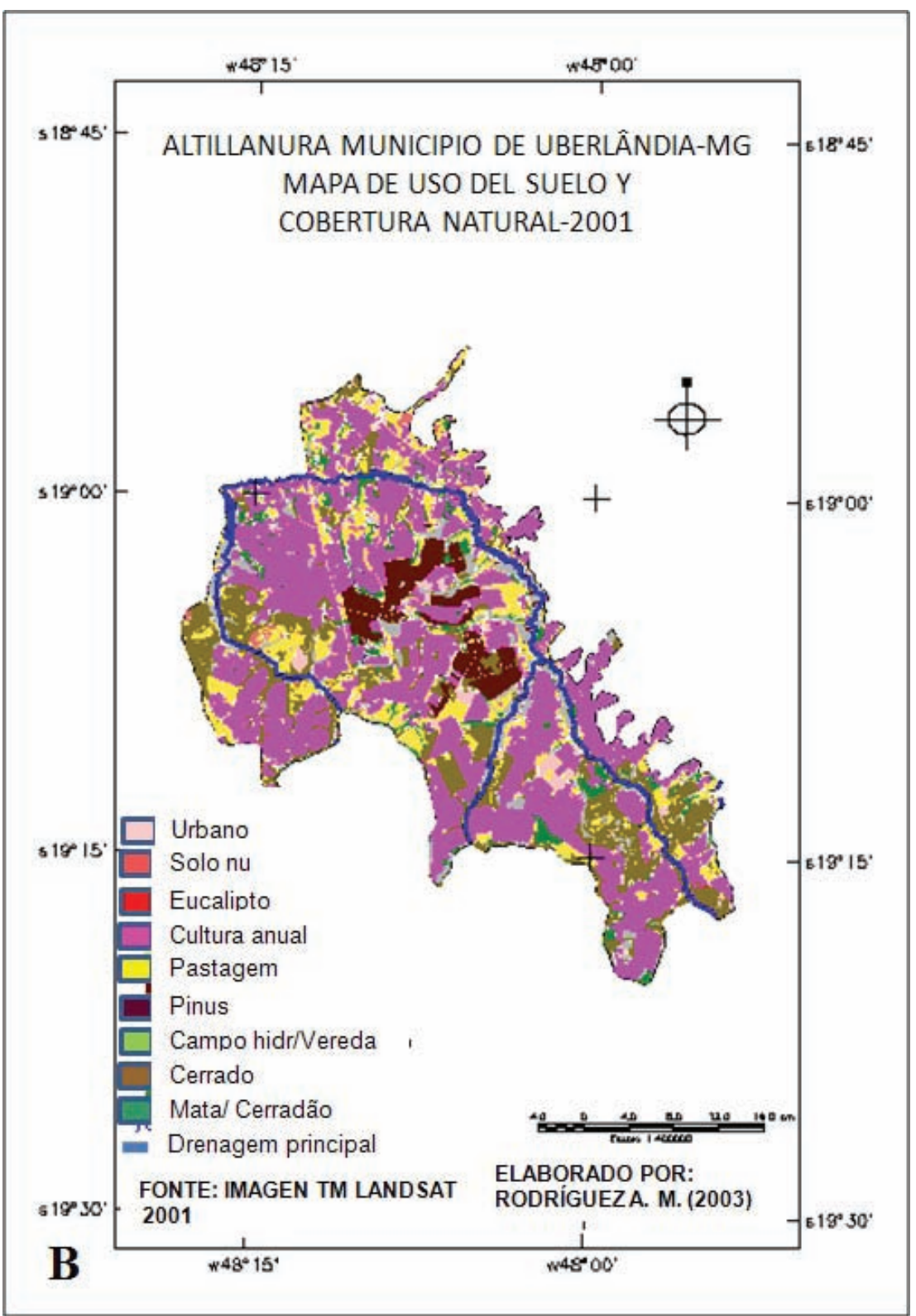

FIGURA 7: Mapa de uso del suelo y cobertura natural de la altillanura de Puerto López

(A) y mapa de uso del suelo y cobertura natural de la altillanura de Uberlândia (B).

En Uberlândia, han cambiado el sistema convencional por el de Siembra Directa, en la mayor parte de áreas cultivadas. Los cultivos a que se hace referencia son: café, maíz, yuca, fríjol, algodón, soya, frutales, y reforestación (ver FIGURA 7).

\section{IMPACTO}

Este estudio muestra que existe variadas e im- portantes diferencias entre los municipios de Puerto López (Colombia) y Uberlândia (Brasil); diferencias en cuanto a la geología, a los suelos y uso de las tierras $\mathrm{y}$ cobertura vegetal natural $\mathrm{y}$, semejanzas en cuanto a las unidades geomorfológicas. Este hecho hace que sea reconsiderada la idea de hacer transferencias de paquetes tecnológicos no modificables, con relación a las condiciones propias de los lugares en los cuales serán implementados. 
La geología, geomorfología, pedología y uso de la tierra en las municipalidades de Puerto López (Colombia) y Uberlândia (Brasil) Maryory Rodríguez Atehortúa, Yolanda Rubiano Sanabria, Jorge Luis Silva Brito, Sílvio Carlos Rodrigues

\section{CONCLUSIONES}

El clima representa un factor determinante para el uso, manejo y conservación del suelo; sin embargo, es necesario hacer el análisis integrado de todos los factores actuantes en la formación del mismo. También es importante conocer la composición (litología) del material parental y su susceptibilidad al intemperismo, ya que esta característica determina el grado de influencia de las dinámicas que ocurren en el suelo, ya sea de tipo mecánico (labranza), biológico o natural.

La variabilidad de tipos de suelos se dan tanto en áreas pequeñas como en áreas grandes; en las primeras, es preciso hacer tratamientos diferentes de manejo y conservación. Es evidente, entonces, que en áreas grandes, con variaciones también del clima y de la geología, no es recomendable usar deliberadamente los mismos métodos o tecnologías para la producción agrícola. Puede suceder que en dos áreas diferentes se den los mismos biomas, como en este caso, en el que se cuenta con vegetación de cerrado/sabana, pero no quiere decir, como ya se comprobó en este trabajo, que los tipos de manejo puedan ser los mismos; ya que los tipos de suelos, la geología y el clima son diferentes.

Fue posible determinar la existencia de variadas e importantes diferencias entre Puerto López y "Uberlândia", en cuanto a los factores biofísicos mencionados.

\section{REFERENCIAS}

AMEZQUiTA, E. Propiedades Físicas de los Suelos de los Llanos Orientales y sus Requerimientos de Labranza. In: ENCUENTRO NACIONAL DE LABRANZA DE CONSERVACION. Memórias. Villavicencio - Meta, Colômbia, 1998.

AMEZQUITA, E.; HOYOS, PH.; QUINTERO, M. Indicadores de respuesta: capa arable y arboles de decisión. In: TALLER NACIONAL SOBRE INDICADORES DE CALIDAD DEL SUELO. Conceptos y Principios Aplicados a la Evaluación de la Degradación de las Tierras. Memórias. Palmira: 2004.

RODRÍGUEZ, M. Uso de SIG como instrumento de apoyo a la planificación agrícola en complemento al ordenamiento territorial del município de Puerto López, Meta. 2000. 140p. Tesis (Ingeniero Agrícola) - Universidad del Valle, Facultad de Ingeniería. Santiago de Cali: Universidad Nacional de Colômbia Sede/Universidad del Valle, 2000.

BACCARO, C. A. D. As unidades geomorfológicas e a erosão nos chapadões do Município de Uberlândia. Sociedade \& Natureza, Uberlândia, v. 6 (n. 11 e 12), p. 19-33, jan./dez. 1994.

BUOL, S. W.; HOLE, F. D.; McCRACKEN, R. J. Soil genesis and classification. 3. ed. Ames: Iowa State University Press, 1989.

EMBRAPA. Levantamento de reconhecimento de média intensidade dos solos e avaliação da aptidão agrícola das terras do Triângulo Mineiro. Rio de Janeiro, Boletim de Pesquisa, n. 1, 1982.

EMBRAPA. Sistema brasileiro de classificação de solos. Brasília: Embrapa, 1999.

FRANCO, H. E. C. Fundamentos para el Conocimiento y manejo de suelos agrícolas. Tunja: Instituto Universitario Juan de Castellanos, 1998.

GARCES, P. H., AMÉZQUITA, E. \& LÓPEZ, D. L. M. Mejoramiento de las características del suelo y su efecto en la productividad en dos Suelos de la Altillanura Plana del departamento del Meta. TALLER NACIONAL SOBRE INDICADORES DE CALIDAD DEL SUELO. Conceptos y Principios Aplicados a la Evaluación de la Degradación de las Tierras. Memórias. Palmira - Valle, Colombia, 2004.

GONTIJO, I. Avaliação de atributos físicos em solo de cerrado sob cafeicultura em dois sistemas de manejo de plantas espontâneas, utilizando testes de hipóteses e geoestatística. 2003. 83f. Dissertação (Mestrado Solos e Nutrição de plantas) - Universidade Federal de Uberlândia, Instituto de Ciências Agrárias/ Programa de Pós-Graduação em Agronomia, Uberlândia, 2003.

Sociedade \& N atureza, U berlândia, 22 (2): 329-345, ago. 2010 
INFORME AGROPECUÁRIO. Sistema estadual de pesquisa agropecuária: Benchmark Soils Project, Base cientifica para transferência de tecnologia agricola. Ano 6, n. 61., EPAMIG, ESAL, UFMG, UFV, Janeiro 80 - Belo Horizonte, Brasil, 1980.

IGAC - INSTITUTO GEOGRAFICO "AGUSTÍN CODAZZI". Zonificación Ambiental del Eje Apaporis-Tabatinga (PAT). Santafé: Sudirección agrológica, 1997.

Estudio general de suelos de los municípios de Cabuyaro, Fuente de Oro, Puerto López, San Carlos de Guaroa y la Inspección de Barranca de Upia. Bogotá: Ministerio de Hacienda y Crédito Público, 1978.

JORGE, R. F., BORGE, E.N.; PASSOS, R. R., RODRIGUES, G. M., GONTIJO, I., SILVA da. C. A., NASCENTES, I. S. de, CORRÊA, G. F. Avaliação de Atributos Químicos e Físicos em Solo de Cerrado Submetido a Diferentes Sistemas de Manejo. Grupo de Pesquisa da Universidade Federal de Uberlândia, Uberlândia - MG, 2003.

LIBAULT, C. O. A. Os quatro níveis da pesquisa geográfica. Métodos em questão. São Paulo: USP/IG, 1971.

ROSS, J. L. S. O Registro Cartográfico dos Fatos Geomórficos e a Questão da Taxonomia do Relevo. Revista do Departamento de Geografia. FFLCH-USP, São Paulo, n. 6, p.17-29, 1992.

ROSOLEM, C. A.; FERNANDEZ, E. M.; ANDREOTTI, M.; CRUSCIOL, C. A.C. Crescimento radicular de plântulas de milho afetado pela resistência do solo à penetração. Pesquisa Agropecuária Brasileira, Brasília, v.34, n.5, p.821-828, 1999.

STONE, L. F., CLEBER, M. G. E MOREIRA, J.A.A. Compactação do Solo na Cultura do Feijoeiro I: efeitos nas propriedades físico-hídricas do solo. Revista Brasileira de Engenharia Agrícola e Ambiental, v.6, n.2, p.207-212, 2002. Campina Grande, PB, DEAg/ UFCG. Disponível em: < http://www.agriambi.com. br $>$. Acesso em: nov.2004. 